\title{
Identifying potentially cost effective chronic care programs for people with COPD
}

\author{
L M G Steuten' \\ K M M Lemmens ${ }^{2}$ \\ A P Nieboer ${ }^{2}$ \\ H JMVrijhoef ${ }^{3}$
}

'Maastricht University Medical Centre, School for Care and Public Health Research, Department of Health, Organisation, Policy and Economics, Maastricht, The Netherlands; ${ }^{2}$ Erasmus University Medical Centre, Institute of Health Policy and Management, Rotterdam, The Netherlands; ${ }_{3}^{3}$ Maastricht University Medical Centre, School for Care and Public Health Research, Department of Integrated Care, Maastricht, The Netherlands
Correspondence: L M G Steuten Maastricht University Medical Centre, School for Care and Public Health Research, Department of Health, Organisation, Policy and Economics, Maastricht, The Netherlands.

Tel 003I 433882456

Fax 003। 43 3884I62

Email lotte.steuten@beoz.unimaas.nl
Objective: To review published evidence regarding the cost effectiveness of multi-component COPD programs and to illustrate how potentially cost effective programs can be identified.

Methods: Systematic search of Medline and Cochrane databases for evaluations of multicomponent disease management or chronic care programs for adults with COPD, describing process, intermediate, and end results of care. Data were independently extracted by two reviewers and descriptively summarized.

Results: Twenty articles describing 17 unique COPD programs were included. There is little evidence for significant improvements in process and intermediate outcomes, except for increased provision of patient self-management education and improved disease-specific knowledge. Overall, the COPD programs generate end results equivalent to usual care, but programs containing $\geq 3$ components show lower relative risks for hospitalization. There is limited scope for programs to break-even or save money.

Conclusion: Identifying cost effective multi-component COPD programs remains a challenge due to scarce methodologically sound studies that demonstrate significant improvements on process, intermediate and end results of care. Estimations of potential cost effectiveness of specific programs illustrated in this paper can, in the absence of 'perfect data', support timely decision-making regarding these programs. Nevertheless, well-designed health economic studies are needed to decrease the current decision uncertainty.

Keywords: chronic care management, COPD, cost-effectiveness, review

\section{Introduction}

Chronic care programs for people with chronic obstructive pulmonary disease (COPD), such as the chronic care model ${ }^{1}$ and disease management programs ${ }^{2}$ are increasingly implemented in daily health care ${ }^{3,4}$ in response to the growing burden of COPD on societies worldwide. ${ }^{5}$ The aim of these programs is, generally, to improve processes and outcomes of care whilst making a more efficient use of scarce health care resources, or even generate cost savings.

The disease management approach as described by the Disease Management Association of America (DMAA) highlights three components: the central care delivery and leadership roles of the primary care physician; the critical importance of patient activation, involvement and personal responsibility; and the patient focus and capacity expansion of care coordination provided through wellness, disease and chronic care management programs. ${ }^{2}$ The chronic care model (CCM) identifies essential components that encourage high-quality chronic disease care, involving the community and health system and including self-management support, delivery system design, decision support, and clinical information systems. ${ }^{6}$

Notwithstanding the intuitive appeal of these approaches, the current evidence regarding their efficacy, effectiveness and cost effectiveness is severely limited by the amount and quality of well-designed studies and the evidence that has been published 
so far reveals results that are far below expectations. ${ }^{7}$ Indeed, the systematic reviews of Weingarten, ${ }^{8}$ Ofman, ${ }^{9}$ and Mattke ${ }^{10}$ consistently show that disease management is less effective for COPD than it is for chronic conditions such as diabetes, congestive heart failure and depression.

By specifically focussing on COPD, however, the systematic review of Adams and colleagues ${ }^{11}$ demonstrated that patients who received two or more CCM components had lower rates of hospitalizations and emergency/unscheduled visits, and shorter length of hospital stay compared with control groups. This may indicate that, despite earlier less encouraging findings, a scope for COPD care programs to generate the necessary improvements in COPD care does exist, providing these packages are truly comprehensive, multifaceted and well co-ordinated. However, since even the proven effective but less comprehensive disease management and chronic care programs struggle to demonstrate their economic benefits, ${ }^{7,9-11}$ and because more comprehensive programs are likely to come at an even higher opportunity cost than the less comprehensive ones, the need for rigorous studies and timely economic evaluations can hardly be underestimated. Furthermore, with innovative industries and health care practices greatly outpacing academic research in this area and considering the mounting health care costs, there is a need to estimate the potential cost effectiveness of COPD care programs, even in the absence of the 'ideal' clinical and economic data. ${ }^{12}$ This study therefore first provides an update of the published evidence regarding the effectiveness and cost effectiveness of multi-component COPD care programs (ie, programs consisting of $\geq 2$ components of disease management or the chronic care model). Secondly, we illustrate how the likely short and long term cost effectiveness of a particular program can be estimated with limited data available; the latter mainly with the aim to support timely decision-making, rather than providing the most precise estimates possible. ${ }^{13,14}$

\section{Methods}

\section{Literature search}

Medline and Cochrane databases were electronically searched for English-language articles published between January 1995 and September 2007 describing evaluations of disease management or chronic care model interventions for adults with mild, moderate, severe, or very COPD.

Search terms included combinations of MeSH terms and text words, as described in Table 1. The search was further expanded by hand searching the references of identified articles.

\section{Study selection and data extraction}

Two reviewers (KL and LS) independently selected studies for inclusion based on the following predetermined criteria: (1) interventions included at least two components of disease management as defined by the $\mathrm{DMAA}^{2}$ or the CCM as described by Wagner ${ }^{1}$ and Bodenheimer and colleagues; ${ }^{15,16}$ (2) studies included a control or comparison group or at least one outcome measured at two points in time (before/after designs), and (3) evaluated relevant process (ie, number of scheduled follow-up contacts with care providers and medication prescribing patterns); intermediate (ie, patients' diseasespecific knowledge, self-efficacy and self-management skills, medication compliance, and social support) or end outcomes (ie, mortality, quality of life, exacerbations, lung function, dyspnoea, symptoms, overall clinical condition, hospital admissions, readmissions and bed days, emergency care admissions, unscheduled outpatient visits, health-related quality of life (HRQL), days off work, COPD-related health care resource use and total costs for COPD-related care). Agreement was examined and disagreements resolved by consensus. Articles describing the impact of specific therapeutic regimens, such as different forms of bronchodilator therapy, pulmonary rehabilitation, oxygen therapy etcetera, were excluded because these interventions are individual parts of clinical guidelines and therefore beyond the scope of this review. Two reviewers (KL and AN) independently extracted the data using a standardized form created for this review; assessed methodological quality of the articles with the so called 'HTA-DM instrument, ${ }^{17}$ and scored this on a 0 to 100 scale with a score $<50$ points indicating poor quality, whilst 50 to 69 points was considered as moderate quality and $\geq 70$ points as good quality. Articles of poor quality were excluded from the review.

Interventions were categorized based on (1) the setting in which they were carried out (ie, community, primary care, secondary care, tertiary care or a combination of these); (2) the population of COPD patients included (ie, at risk, mild, moderate, severe or very severe); (3) the type and number of intervention components (ie, self-management [SMAN]; delivery system design [DSYS]; decision support [DSUP]; clinical information systems [CIS]). As regards the latter we also noted whether the article explicitly named the intervention as being a disease management program or a CCM intervention. If the intervention was stated to be a disease management program and encompassed a clinical 
Table I Search strategy

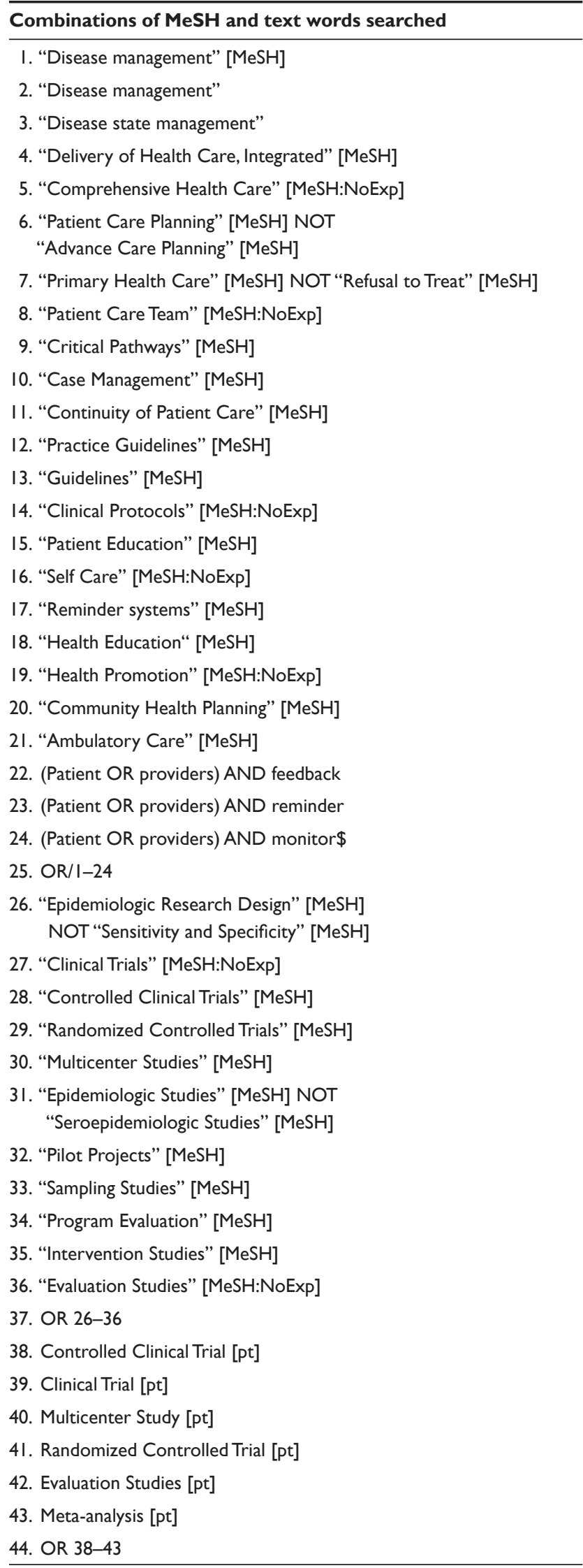

(Continued)
Table I (Continued)

Combinations of MeSH and text words searched
45. 37 OR 44
46. AND "Pulmonary Disease, Chronic Obstructive" [MeSH]
47. 25 AND 45
48. Limit 47 to human
49. Limit 48 to yr $1995-2007$
50. Limit 49 to English

information system, it was additionally registered whether this information system facilitated (a) population identification processes [PIP]; (b) process and outcome measurement, evaluation and management [MEM]; and/or (c) routine reporting and/or feedback loops [RFEED]. ${ }^{2}$

\section{Data analysis}

Extracted data were entered into a spreadsheet $\left(\right.$ Excel $^{\circledR}$; Microsoft, Redmond (WA), US) and analysed in a descriptive way (ie, numbers, frequencies, and percentages). To determine the impact of the interventions, included studies were analysed for statistically significant differences (considering the p-value as applied in the study's analysis). In addition we noted whether the study was sufficiently powered (ie, $\beta \leq 0.2$ ) to detect a statistical significant difference of a 'meaningful' size on the primary study outcome (with 'meaningful' as determined by the authors of the included studies). Further, where the presented data allowed us to, we calculated relative risks (RRs) and their associated $95 \%$ confidence intervals for hospitalization, emergency department visits and other unplanned visits, and mortality. Finally, to illustrate the potential financial viability of the COPD programs, it was explored at what opportunity costs a program might be expected to demonstrate a cost effective use of resources (1) within one year; or (2) in the long term (ie, over the expected remaining life time of the patient population) from a health system's perspective. The exploration was carried out for a selection of programs that reported the necessary data for these analyses.

The short term cost effectiveness analysis was based on the reported changes in hospital and emergency department (re)admissions within one year of follow-up and the associated cost per hospital and/or emergency department (ED) admission. The long-term analysis was based on reported changes in survival and HRQL and evaluated against a range of societal willingness-to-pay (WTP) thresholds for one 'quality-adjusted life year'(QALY). ${ }^{18,19}$ 


\section{Results}

\section{Study retrieval}

The search identified 308 nonduplicative titles. After independent assessment of abstracts and full-texts by two reviewers regarding eligibility, 288 articles were excluded because these (1) did not concern disease or chronic care management in accordance with the definitions of the DMAA or Wagner and colleagues $(n=166)$; or (2) were single component interventions $(n=72)$; or (3) did not employ a control group or report more than one measurement $(n=42)$; or (4) were of poor methodological quality $(n=8)$. The 20 included articles described 17 unique COPD programs. Most articles originate from the US $(n=6 \text {; describing five programs })^{20-25}$ followed by Australia $(\mathrm{n}=4)^{26-29}$ and New Zealand $(\mathrm{n}=2) ;{ }^{30,31}$ Canada $(\mathrm{n}=3 \text {; describing one program })^{32-34}$ the Netherlands $(\mathrm{n}=2) ; 35,36$ Spain $\left(\mathrm{n}=2 ; 3^{37,38}\right.$ one including a Belgian comparator group $\left.{ }^{38}\right)$; and China $(\mathrm{n}=1){ }^{39}$

\section{Study designs and methodological quality}

The 17 studies include 14 randomized controlled trials (RCTs), two nonrandomized controlled trials ${ }^{28,30}$ and one before-after study ${ }^{36}$ (see Table 2). In 11 of the 14 RCTs randomization was performed on the patient level, whereas three RCTs randomized on the level of care delivery centres, ie, general practices, ${ }^{31}$ nursing homes, ${ }^{39}$ or drugstores. ${ }^{25}$

Although 15 studies report the impact of the intervention on resource use, only three evaluated this impact in monetary terms ${ }^{34,36,37}$ and can therefore be considered an economic evaluation. Poole and colleagues ${ }^{30}$ conducted a limited returnon-investment analysis by investigating the reduction in bed days per patient needed in order to pay off the salary costs of the main care providers involved in the program.

Reported study follow-up varies from eight weeks ${ }^{37}$ to two years, ${ }^{22,33,35}$ with most articles reporting a follow-up of 12 months $(n=9) .{ }^{25,28-32,34,36,38}$ Study sample size at baseline varies from $n=32^{30}$ to $n=453,{ }^{25}$ with a mean $( \pm S D)$ sample size of $n=163( \pm 104)$ and a median of $n=155$. Average proportion of patient follow-up is $81 \%( \pm 14 \%)$ in intervention arms and $78 \%( \pm 16 \%)$ in control arms. Six of the 17 included studies demonstrate at least $80 \%$ power for detecting a meaningful statistical significant change in their primary outcome measure ${ }^{25,29,31,32-34,36,38}$ and four studies failed to include sufficient patient numbers as determined by their sample size calculations..$^{20,21,27,35}$ Seven studies did not mention whether their study was sufficiently powered, ${ }^{22-24,26,28,30,37,39}$ but three of these studies include less than 40 patients in each study $\operatorname{arm}^{26,28,30}$ and are most likely underpowered.
Methodological quality of studies is mostly moderate (see Table 2 ), with an overall mean $( \pm \mathrm{SD})$ quality score of $67.6( \pm 9.4)$ points and a median of 65 points. The most frequently observed flaw in included articles is that information on the program itself and the characteristics of the region or institution in which the program has been implemented is lacking or described too briefly, herewith hindering the assessment of external validity of the findings. Further, the time horizon of the evaluations is in almost $50 \%$ of the studies considered too short (ie, less than one year) to adequately capture the potential benefits of essentially nonpharmacological interventions in a patient population suffering from an irreversible and progressing chronic condition.

\section{Study setting and population}

Most programmes are implemented in secondary care and three programs have been implemented across multiple settings (see Table 2).

The study settings reflect the subgroups of COPD patients enrolled in the program, as characterized by the staging system of Global Initiative for Chronic Obstructive Lung Disease (GOLD).$^{40}$ For example, all programs include patients with severe COPD (GOLD 3) who are commonly treated in secondary care, whereas multiple setting programmes encompass a broader range of patients (eg, GOLD 1 to 4)..$^{28,35,36}$

The mean age $( \pm \mathrm{SD})$ of the included study samples ranges from $47.3( \pm 13.9)^{28}$ to $80.4( \pm 6.3)^{21}$ years. Across all included studies, the mean age is $66.4( \pm 7.9)$ with a median of 68.5 years.

\section{Types of programs and included interventions}

All programs include the components self-management and delivery system design. Five programs additionally encompass the component decision support ${ }^{20,21,25,32-34,39}$ and four also include clinical information systems..$^{26,31,36,38}$ Of the four programs that are explicitly referred to as DMPs, three operate a clinical information system that serves to support process and outcomes measurement, evaluation and management. ${ }^{26,31,36}$ In two of these programs this system also facilitates routine reporting and feedback loops, ${ }^{26,36}$ and in one program ${ }^{31}$ the system is further used for population identification processes.

\section{Results on process measures}

The majority of studies describing the number of scheduled outpatient visits and home visits reported no significant 


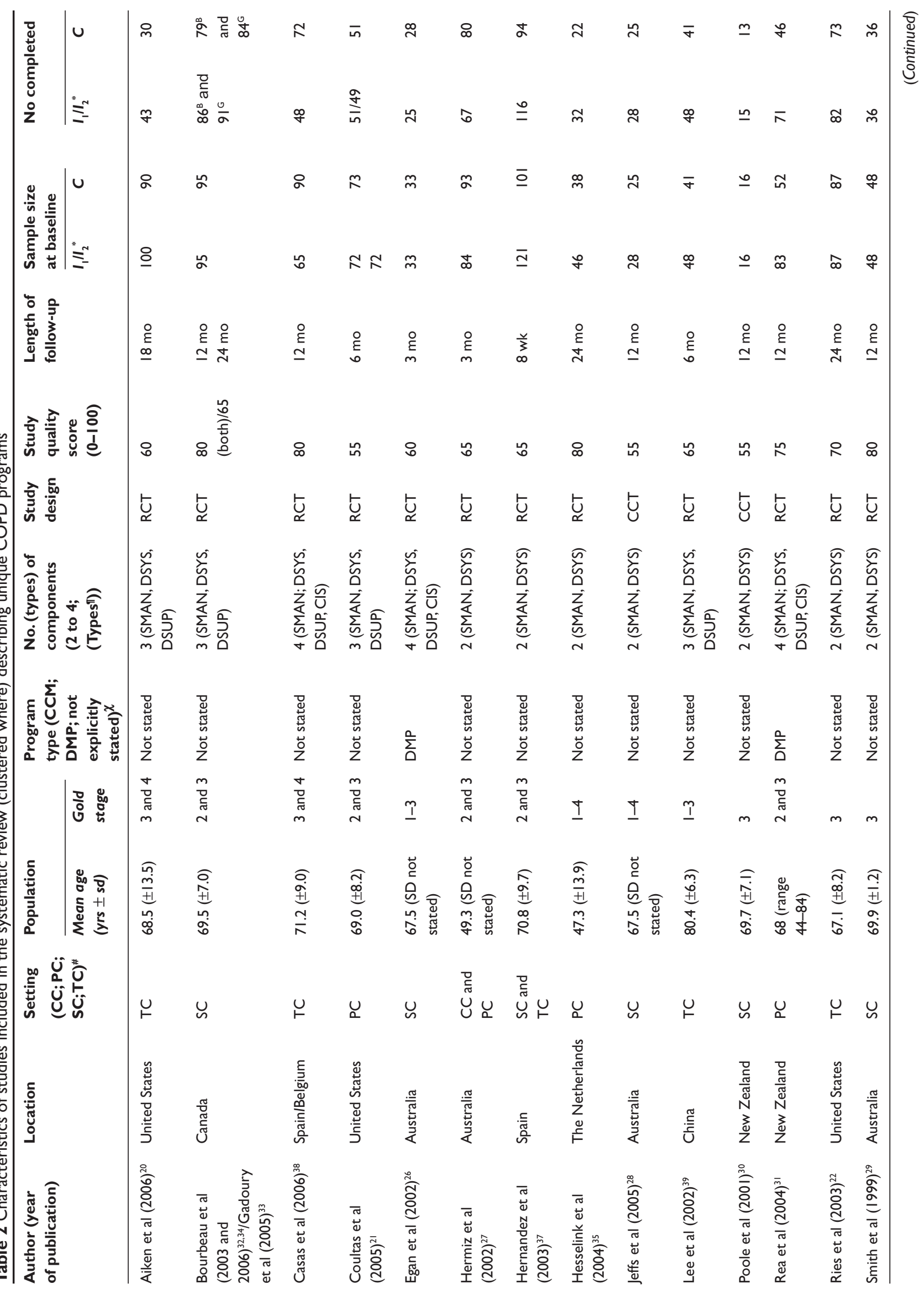




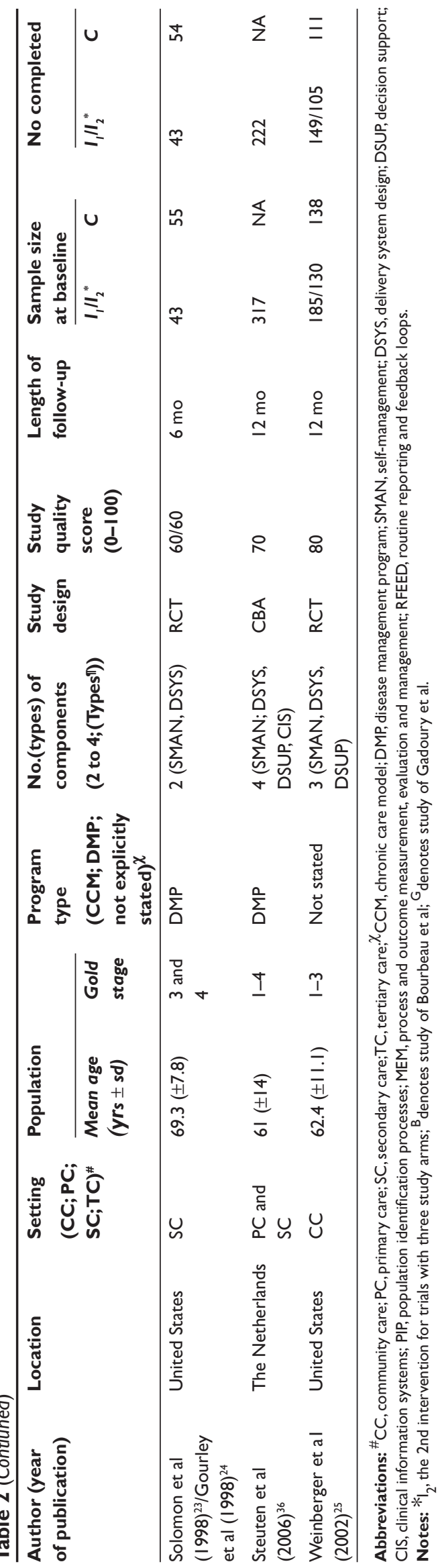

changes for general practitioner (GP), specialist or nurse visits (see Table 3). Medication prescribing patterns (ie, type and amount of COPD medication prescribed) also remained largely the same, except for one study that found a statistical significant lower cost for COPD prescriptions (31\% lower) associated with the intervention. ${ }^{37}$ The amount of patient education provided increased significantly in all studies reporting this process measure. Results for coordination of care were mixed, depending on how coordination was defined and measured, whereas one study reported improved accessibility of care. ${ }^{36}$

\section{Results on intermediate outcomes}

Disease-specific knowledge has been found to improve in four out of five studies measuring this. ${ }^{20,27,36,37}$ Further, patient reported outcomes indicated advanced technical skills (inhalation technique) and self-efficacy in two studies, ${ }^{27,37}$ whereas one study showed improved self-management and medication adherence. ${ }^{36}$ The majority of studies, however, did not detect statistical significant changes as far as self-management behaviour, medication compliance, technical skills/self-efficacy and social support are concerned (see Table 3).

\section{Results on end outcomes}

For all reported end results, the dominating finding is that COPD care management programs generate equivalent outcomes in comparison to usual care and less intense forms of chronic care or disease management. Nevertheless, a few studies have detected a positive impact of their intervention on lung function $(\mathrm{n}=2),{ }^{25,31}$ physical functioning $(\mathrm{n}=3),{ }^{20,22,29}$ and mental functioning $(\mathrm{n}=3){ }^{22,29,39}$ Furthermore, eight ${ }^{20,22,29-32,36,37}$ out of 15 studies reporting on HRQL find statistical significant improvements for (at least some aspects of) this parameter, although these are not always sustained in the longer term. ${ }^{22,32}$ As regards health care utilization, seven studies (eight articles) ) $22,23,30,32,33,35,36,38$ out of 15 studies (19 articles) report a decrease in exacerbation related health care utilization, including ED-visits, hospital (re)admissions and other unscheduled outpatient visits. Three studies ${ }^{34,36,37}$ presented cost data and showed that differences were found on individual cost parameters including higher costs for prescriptions, ${ }^{36,37}$ lower hospitalization-related costs ${ }^{37}$ and lower sick leave costs. ${ }^{37}$ However, none of these studies reported significant changes in total costs.

Negative findings associated with the interventions have also been reported. These include: deteriorated lung 
Table 3 Reported intermediate and end outcomes: measures used and summary of findings

Outcome (n, number of studies reporting the outcome)

Process measures

Scheduled outpatient visits $(n=7)$

Medication prescriptions $(n=5)$

Amount of patient education provided $(n=5)$

Coordination of care $(n=2)$

Accessibility of care $(n=1)$

Intermediate outcomes

Disease specific knowledge $(n=5)$

Self-management behaviour $(n=4)$

Medication compliance $(n=4)$

Technical skills/self-efficacy $(n=4)$

Social support $(n=2)$

End outcomes

Lung function $(n=7)$

Dyspnoea $(n=7)$

Symptoms $(n=9)$

Physical functioning $(\mathrm{n}=10)$

$=>$ Questionnaire based $(\mathrm{n}=8)$

Measures $^{\S}$

Summary of findings [study references]

Physician (GP) office visits ${ }^{[32,21,27,37,36]}$; Specialist/ outpatient hospital visits ${ }^{[32,38,37,22,36]}$; Nurse home visits $^{[38,27,37]}$

Total prescribed COPD-related medication ${ }^{[37,36]}$; new medications prescribed ${ }^{[23]}$; antibiotics ${ }^{[28,31]}$; oral steroids ${ }^{[28,31]}$; domiciliary oxygen ${ }^{[28]}$; inhaled bronchodilators ${ }^{[28]}$

Self-management education ${ }^{[20,36]}$; COPD education $[20,21,27,24]$

Number of GP-arranged follow-ups ${ }^{[27]}$; Patient assessed change in coordination of care ${ }^{[36]}$

Patient assessed change in accessibility of care ${ }^{[36]}$

Deenen's respiratory knowledge

questionnaire ${ }^{[M l, 36]}$;

Self-designed questionnaire (not validated) ${ }^{[20,27,37,24]}$

Self-designed questionnaire (not validated) ${ }^{[27,35,31,36]}$;

Patient-reported smoking cessation ${ }^{[35,31,36]}$; physical activity $^{[36]}$; influenza vaccination ${ }^{[27]}$; pneumococcal vaccination $^{[27]}$

Self-designed questionnaire (not validated) ${ }^{[37,35,36,25]}$;

Single-item ${ }^{[M 2,25]}$ and 4-point Likert scale

questionnaire ${ }^{[M 3,25]}$

COPD Self-Efficacy Scale ${ }^{[M 4,21,35]}$;

Coping style questionnaire ${ }^{[M 5,35]}$;

Inhalation checklist ${ }^{[M 6,35]}$;Walking self-efficacy ${ }^{[M 7,22]}$; Self-designed questionnaire (not validated) ${ }^{[37]}$

MOS social support survey ${ }^{[\mathrm{M} 8,21,26]}$

Post bronchodilators FEV, (litres) ${ }^{[32,31,22,29]}$;

FEV (\% predicted) $)^{[39,31,22,29,36]}$;

FVC (litres) ${ }^{[32]}$; FEV $/$ /FVC (\%) ${ }^{[32,36]}$;

PEF rate (\% predicted) ${ }^{[25]}$

MRC dyspnoea questionnaire ${ }^{[M 9,35]}$;

CRQ-dyspnoea dimension ${ }^{[M / 0,30,31,25]}$;

UCSD Shortness of Breath Questionnaire ${ }^{[M / 1,22]}$;

Baseline and Transition Dyspnoea Indices (interview administered) ${ }^{[M / 2,22]}$;

BORG scale ${ }^{[M / 3,23]}$; Self-developed questionnaire (not validated) ${ }^{[29]}$

SGRQ-symptoms ${ }^{[M 25,32,21,26,27,37]}$; Memorial Symptom Assessment Scale ${ }^{[M 26,20]}$; General Health Questionnaire [M23,39]; Symptoms checklist ${ }^{[M 27,35]}$; Self-developed questionnaire (not validated) ${ }^{[23]}$

SF-36 physical functioning[M/4,20,21,31]; SF- 12 physical functioning ${ }^{[M / 5,37]}$; Barthel Index ${ }^{[M / 6,39]}$; RAND-36 physical component ${ }^{[M 17,22]}$;

COOP (adapted physical functioning item) ${ }^{[M / 8,29]}$; Health Status Questionnaire ${ }^{[M / 9,24]}$

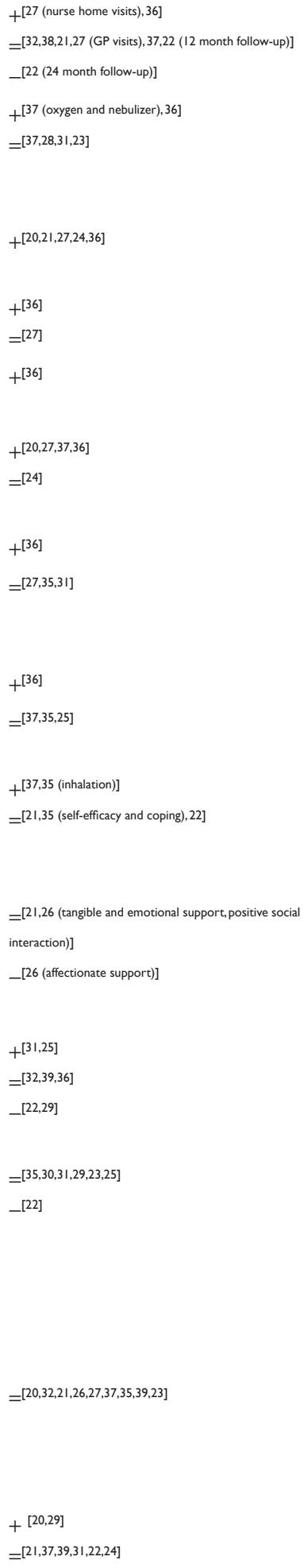

(Continued) 
Table 3 (Continued)

\begin{tabular}{|c|c|c|}
\hline $\begin{array}{l}\text { Outcome (n, number of studies } \\
\text { reporting the outcome) }\end{array}$ & Measures $^{\S}$ & $\begin{array}{l}\text { Summary of findings [study } \\
\text { references] }\end{array}$ \\
\hline$=>$ Performance based $(n=2)$ & $\begin{array}{l}\text { 6-minute walk test }{ }^{[\mathrm{M} 20,32,22]} \text {; Shuttle Walk Test }{ }^{[M 21,31]} \text {; } \\
\text { Treadmill Test }{ }^{[22]}\end{array}$ & $\begin{array}{l}+[22(12 \text { month follow-up })] \\
=[32,31,22(24 \text { month follow-up })]\end{array}$ \\
\hline Mental functioning $(n=I I)$ & $\begin{array}{l}\text { SF-36 mental health }{ }^{[M / 4,20,21,31]} ; \text { HAD }^{[M 22,26,30]} \text {; Health } \\
\text { Status Questionnaire }{ }^{[M / 9,23]} ; \text { SF- I } 2 \text { mental health } \\
\text { [M/5,37]; General Health Questionnaire }{ }^{[M 23,39]} \text {; } \\
\text { CRQ-emotion dimension }{ }^{[M / 0,30,31,25]} \text { CED-Depression } \\
\text { Scale }{ }^{[M 24,22]} \text {; RAND-36 mental component }{ }^{[M / 7,22]} \text {; } \\
\text { COOP emotion components }{ }^{[M / 8,29]}\end{array}$ & $\begin{array}{l}+[39,22(12 \text { month follow-up), 29] } \\
=[20,21,26,37,30,31,22(24 \text { month follow-up) }, 29,23,25]\end{array}$ \\
\hline Health-related Quality of Life & 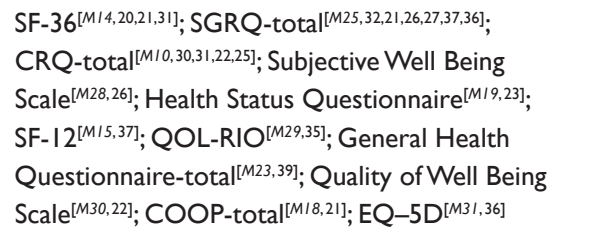 & $\begin{array}{l}+[20,32 \text { (4 month follow-up), } 37 \text { (SGRQ), } \\
30,31 \text { (CRQ-fatigue and mastery), } \\
22 \text { (I2 month follow-up), } 29,36 \text { (EQ-5D)] } \\
={ }^{[32} \text { (12 month follow-up), 21,26,27,37 (SF-12), 35,39,31 (SF-36), } \\
22 \text { (24 month follow-up), } 36 \text { (SGRQ), 25] }\end{array}$ \\
\hline Health care utilization and costs $(n=19)$ & 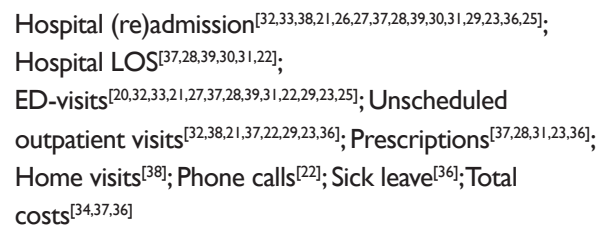 & $\begin{array}{l}+[37 \text { (prescriptions), } 28 \text { (hospital LOS), } 36 \text { (prescriptions)] } \\
={ }^{[20,34,38,21,26,27,35 \text { (outpatient visits), } 28,39,30,31,} \\
22 \text { (ED-visits), } 29,23,36 \text { (total costs), } 25] \\
-[32,33,38 \text { (readmissions), } 35,30 \text { (hospital LOS), } \\
22,23 \text { (outpatient visits), 36] }\end{array}$ \\
\hline Mortality $(n=14)$ & All causes death $[20,32,34,33,38,21,27,37,35,30,31,22,29,25]$ & $=[20,32,34,33,38,21,27,37,35,30,31,22,29,25]$ \\
\hline
\end{tabular}

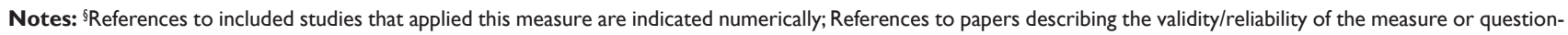
naire are indicated with $M x$.

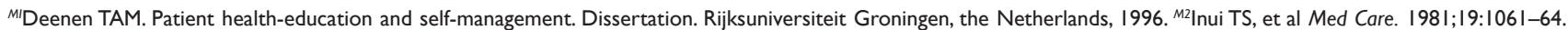

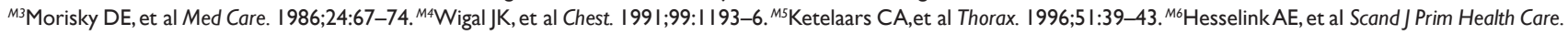

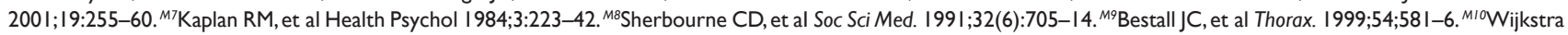

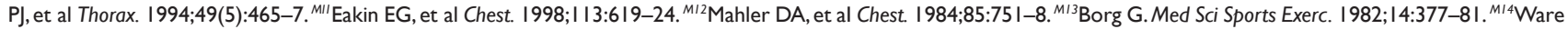

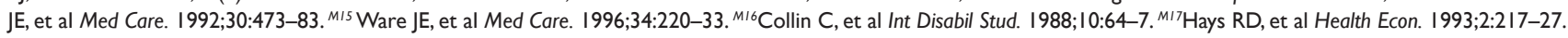

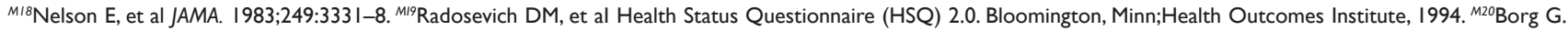

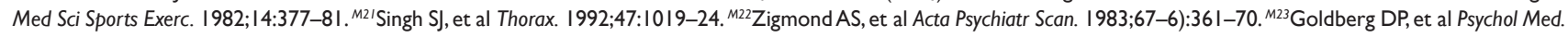

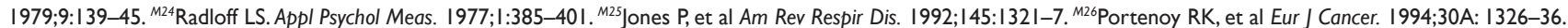

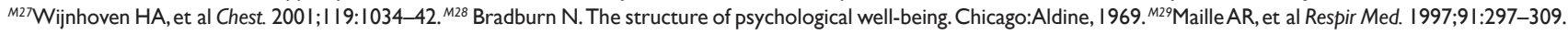

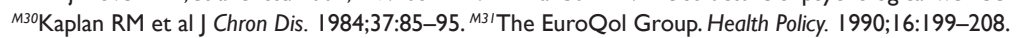

function, increased dyspnoea, increased medication use and longer hospital length of stay in comparison with the control groups. An overview of results on end outcomes is presented in Table 3.

\section{Relative risks for hospitalizations, emergency department/unscheduled visits, and mortality}

The observed relative risks (RRs) for hospitalization of intervention patients versus control patients vary widely (from 0.64 to 1.50 ; see Table 4) and only three ${ }^{31,32,38}$ are statistically significant at a $95 \%$ confidence interval $(95 \%$ CI). The findings from these three studies all favour the intervention group. Moreover, these three programs include three ${ }^{32}$ chronic care components (ie, DSUP on top of SMAN and DSYS) or four ${ }^{31,38}$ (ie, DSUP and CIS in addition to SMAN and DSYS) components, whereas all other programs for which a RR could be calculated encompass SMAN and DSYS only. As regards ED and other unplanned outpatient visits, the RRs vary from 0.28 to 2.28 (see Table 4), with two studies ${ }^{32,37}$ observing a statistical significant reduction in ED-visits favouring the intervention. The RRs for mortality vary from 0.31 to 1.20 (see Table 5), and none of these reach statistical significance at a $95 \% \mathrm{CI}$.

\section{Illustration Ia: Potential short term cost effectiveness based on reduced hospital admissions only}

In the study of Rea and colleagues, a RR for hospital admissions in the intervention group of 0.81 (95\% CI: 0.59-0.83) was observed. ${ }^{31}$ Also the mean length of hospital stay was reportedly shorter in the intervention group than in the control group (1.1 vs 4.0 days). The cost of a hospital bed 
Table 4 Relative risks of hospitalization and emergency department (ED)/unscheduled visits for intervention patients versus control patients

\begin{tabular}{|c|c|c|c|c|c|}
\hline Source & Study setting & $\begin{array}{l}\text { Included } \\
\text { GOLD-stages }\end{array}$ & $\begin{array}{l}\text { Number of } \\
\text { components }\end{array}$ & $\begin{array}{l}\text { Relative risk of } \\
\text { hospitalization } \\
\text { (95\% Confidence } \\
\text { interval) }\end{array}$ & $\begin{array}{l}\text { Relative risk of EDI } \\
\text { unscheduled visits } \\
\text { (95\% Confidence } \\
\text { interval) }\end{array}$ \\
\hline Bourbeau et al $(2003)^{32}$ & Secondary care & 2 and 3 & 3 & $0.64(0.45-0.91)$ & $0.64(0.48-0.86)$ \\
\hline Casas et al $(2006)^{38}$ & Tertiary care & 3 and 4 & 4 & $0.67(0.49-0.91)$ & NA \\
\hline Gourley et al $(1998)^{24}$ & Secondary care & 3 and 4 & 2 & NA & I.I2(0.44-5.43) \\
\hline Hermiz et al $(2002)^{27}$ & $\begin{array}{l}\text { Community and } \\
\text { primary care }\end{array}$ & 2 and 3 & 2 & $1.27(0.66-2.43)$ & $0.28(0.06-1.27)$ \\
\hline Hernandez et al $(2003)^{37}$ & $\begin{array}{l}\text { Secondary and } \\
\text { tertiary care }\end{array}$ & 2 and 3 & 2 & $0.74(0.45-\mid .2 I)$ & $0.44(0.22-0.86)$ \\
\hline Jeffs et al $(2005)^{28}$ & Secondary care & $1-4$ & 2 & $1.50(0.84-2.67)$ & NA \\
\hline Poole et al $(200 \mathrm{I})^{30}$ & Secondary care & 3 & 2 & I.08 (0.75-I.57) & NA \\
\hline Rea et al $(2004)^{31}$ & Primary care & 2 and 3 & 4 & $0.81(0.59-0.83)$ & $0.46(0.16-1.37)$ \\
\hline Smith et al $(1999)^{29}$ & Secondary care & 3 & 2 & I.0I $(0.82-1.26)$ & $2.28(0.96-5.43)$ \\
\hline
\end{tabular}

day was approximately NZ\$700 in 2003. From this it can be calculated that the average cost of hospitalization per COPD patient per year for the conventional care strategy would be:

$$
4 * \mathrm{NZ} \$ 700=\mathrm{NZ} \$ 2800
$$

whereas the average annual cost of hospitalization per COPD patient in the intervention group would be:

$$
0.81 *(1.1 * \mathrm{NZ} \$ 700)=\mathrm{NZ} \$ 623.7
$$

Thus, based on the observed reduction in hospital admissions and hospital length of stay, and assuming all else equal, a cost effective use of resources from a health systems perspective for this program will be achieved if it can be delivered in a way that the incremental costs of the program

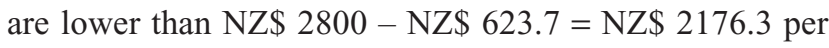
patient per year.

\section{Illustration Ib: Potential short term cost effectiveness based on changes in hospital admission and ED visits}

In the study of Hermiz and colleagues, ${ }^{27} \mathrm{a}$ RR for hospital admissions of 1.27 (95\% CI: 0.66-2.43) and a RR for ED visits of 0.28 (95\% CI: 0.06-1.27) was observed for the intervention group as compared for the controls. The cost of a hospital bed is approximately AUS\$ 320 and the costs of an ED visit AUS\$ 100. ${ }^{41}$ Assuming the length of hospital stay is 2.4 days $^{41}$ and is equal in
COPD care management and usual care, the average cost of hospitalizations per patient per year in a usual care strategy would be:

$$
2.4 * \text { AUS\$ } 320=\text { AUS\$ } 768
$$

Further, assuming an average of 0.5 ED visits per COPD patient per year, ${ }^{41}$ the cost of ED visits in a usual care strategy would be:

$$
0.5 * \text { AUS\$ } 100=\text { AUS } \$ 50
$$

In the COPD care program, the annual cost of hospitalizations per patient would be:

$$
1.27 *(2.4 * \text { AUS\$ 320) }=\text { AUS\$ } 975.36
$$

and the average annual cost of ED visits per COPD patient would be:

$$
0.28 *(0.5 * \text { AUS\$100) }=\text { AUS\$ } 14
$$

Based on the observed increase in hospital admissions and reduction in ED visits, and assuming all else equal, this COPD program would be considered cost effective from a health systems perspective if its incremental costs would be lower than AUS\$ 818 - AUS\$ 989.36=-AUS\$ 171.36 per patient per year. This means that on other aspects of the program savings of at least AUS\$171.36 per patient per year should be generated in order to set off the additional hospitalization costs, and even more to potentially achieve a return on investment. ${ }^{42}$ 
Table 5 Relative risks of mortality for intervention patients versus control patients

\begin{tabular}{|c|c|c|c|c|}
\hline Source & Study setting & $\begin{array}{l}\text { Included } \\
\text { GOLD-stages }\end{array}$ & $\begin{array}{l}\text { Number of } \\
\text { components }\end{array}$ & $\begin{array}{l}\text { Relative risk } \\
\text { (95\% Confidence } \\
\text { interval) }\end{array}$ \\
\hline Aiken et al $(2006)^{20}$ & Tertiary care & 3 and 4 & 3 & $1.20(0.60-2.40)$ \\
\hline Bourbeau et al $(2003)^{32}$ & Secondary care & 2 and 3 & 3 & $0.56(0.19-1.60)$ \\
\hline Casas et al $(2006)^{38}$ & Tertiary care & 3 and 4 & 4 & $1.19(0.59-2.39)$ \\
\hline Coultas et al $(2005)^{21}$ & Primary care & 2 and 3 & 4 & $\mathrm{I} .0 \mathrm{I}(0.2 \mathrm{I}-4.86)^{*}$ \\
\hline Gadoury et al $(2005)^{33}$ & Secondary care & 2 and 3 & 3 & $0.7 \mathrm{I}(0.37-\mathrm{I} .38)$ \\
\hline Hermiz et al $(2002)^{27}$ & $\begin{array}{l}\text { Community and } \\
\text { primary care }\end{array}$ & 2 and 3 & 2 & $1.00(0.43-2.33)$ \\
\hline Hernandez et al $(2003)^{37}$ & $\begin{array}{l}\text { Secondary and } \\
\text { tertiary care }\end{array}$ & 2 and 3 & 2 & $0.60(0.20-1.82)$ \\
\hline Poole et al $(200 \mathrm{I})^{30}$ & Secondary care & 3 & 2 & $0.33(0.04-2.87)$ \\
\hline Rea et al $(2004)^{31}$ & Primary care & 2 and 3 & 4 & $0.31(0.26-1.65)$ \\
\hline Ries et al (2003)22 & Tertiary care & 3 & 2 & $0.98(0.43-2.22)$ \\
\hline Smith et al $(1999)^{29}$ & Secondary care & 3 & 2 & $1.14(0.45-2.90)$ \\
\hline
\end{tabular}

Note: *RR for case management versus usual care.

\section{Illustration 2a: Potential long term cost effectiveness based on changes in health-related quality of life only}

The study of Steuten and colleagues reports an increase in HRQL of 0.02 (from 0.67 at baseline to 0.69 at 12 months follow-up). ${ }^{36}$ Assuming 1) no difference in mortality between usual care and the intervention; 2) an average life expectancy of 75 years (ie, plus 14 years from the sample's baseline age of 61 years); and 3) a sustained relative intervention effect on HRQL over the life time of a patient, then, all else equal, the incremental QALYs over the remaining life time of one patient in the intervention versus the control strategy would be:

$$
14 * 0.02=0.28 \text { QALYs }^{1 *}
$$

At a societal WTP of $€ 30,000$ per QALY this means that the program would be considered cost effective if its incremental costs do not exceed $0.28 * € 30,000=€ 8400$ per patient over his/her remaining lifetime or on average $€ 600$ per patient per year $(€ 8400 / 14)$. Similarly, if the WTP for a QALY would be $€ 50,000$ then the cost effectiveness gap for the program, given its incremental effectiveness on HRQL of 0.28 , would be as high as $€ 14,000$ per patient over his/her remaining lifetime (or $€ 1,000$ annually) and at a WTP of $€ 20,000$ only $€ 5600$ over lifetime (or $€ 400$ per year).

\footnotetext{
${ }^{1, *}$ For reasons of simplicity, future benefits and costs are not discounted in this illustration.
}

\section{Illustration 2b: Potential long term cost effectiveness based on changes in health related quality of life and survival}

From the paper of Hernandez and colleagues, ${ }^{37}$ it can be derived that the average score on the physical component of the Short Form 12 (SF-12) is 0.3770 in the intervention group and 0.3590 in the control group (scores converted from a $0-100$ to a $0-1$ scale). The incremental HRQL for the interventions group on the physical domain is thus +0.0180 . On the mental domain of the SF12, the average scores are 0.4600 and 0.4395 in the intervention and control group respectively, thus an incremental HRQL for the intervention group of 0.0205 on the mental domain. It is assumed that the incremental and physical domains are additive ${ }^{43}$ Given that the average age of the study subjects is 71 years at baseline, the RR for mortality is 0.6 for intervention vs control group, and assuming an average life expectancy of 75 years when receiving conventional care (so +4 years from baseline), then, all else equal, the mean difference in QALYs over the remaining life time of one patient in the intervention versus the usual care strategy would be:

$$
\begin{aligned}
(4 / 0.6) *(0.0180+0.0205)= & 6.66676 * 0.03085=0.256 \\
& \text { QALYs }^{2 *}
\end{aligned}
$$

At a societal WTP of $€ 30,000$ per QALY this means that the program would be considered cost effective if its incremental

\footnotetext{
${ }^{2, *}$ For reasons of simplicity, future benefits and costs are not discounted in this illustration.
} 
costs would not exceed $0.256 * € 30,000=€ 7680$ per patient over his/her expected lifetime of 6.7 years. At a WTP of $€ 50,000$ the cost effectiveness gap would be $€ 12,800$ and at a WTP of $€ 20,000$ this gap would be $€ 5,120$ per patient over the expected lifetime.

\section{Discussion}

Notwithstanding their relentless efforts and investments, the innovators behind chronic care programs for people with COPD keep struggling to articulate the value of these programs to patients, care providers and payers in terms of 'proof' rather than 'belief'. This study therefore aimed to update and critically review the current evidence base as regards the impact of multi-component COPD care programs on process, intermediate and end results of care. Furthermore, in order to support timely decision-making regarding (further) investment in such programs, we illustrated how potentially cost effective programs can be identified, even in the absence of full-blown health economic evaluations.

Starting with the effectiveness of multi-component COPD programs on processes and intermediate outcomes of care, we find little evidence of significant improvements. Although significantly more patient self-management education is provided as part of the COPD programmes, and patient's disease-specific knowledge indeed improves as a result of this, on the whole there is little proof that this better knowledge actually translates into significant and sustained behavioural changes, as for example smoking cessation, or in better medication adherence and self-efficacy within one or two years follow-up. This finding is in accordance with results from previous reviews, ${ }^{11,44}$ but nevertheless dissatisfying. Since smoking cessation is still regarded the most effective way to slow down the disease progression, more emphasis should be placed on other ways to encourage smokers to quit than purely providing education. Reimbursing the costs of smoking cessation therapy, for example, has been proven an efficacious ${ }^{45}$ and cost effective ${ }^{46}$ way to significantly increase the prolonged abstinence rate.

Also on end outcomes of care (including clinical outcomes, dyspnoea, symptoms and physical and mental functioning, HRQL, mortality, health care utilizations and costs), the COPD care programs merely demonstrate equivalence to usual care. As regards hospital (re)admissions, which are commonly the primary outcome of evaluation, it is worth noting that only for the three programs that encompass $\geq 3$ components of chronic care management, the associated RRs for hospital readmission were statistically significant, and favoured the intervention strategy, whereas for programs encompassing two components no statistical significant changes were detected. Given that the patient populations included in these studies were comparable to the other studies in terms of sample size, COPD severity and age, and that all programs encompassed the components 'delivery system design' and 'self-management support', this might suggest that programs that additionally encompass the components 'clinical information system' and/or 'decisionsupport' are more likely to be effective in reducing hospital (re)admissions than the more limited packages. Although this suggestion should be interpreted with caution since the programs were not compared head to head and RRs could only be calculated for nine of the 17 studies, this may start to shed more light on the important issues raised in the review of Adams and colleagues ${ }^{11}$ about the relative value of each of the chronic care components for COPD, and the incremental value of combining more than two components in one COPD program. Further, the fact that the component 'decision-support' is lacking in most programs might indicate that clinical guidelines, which have shown to reduce unjustified variety in care and improve delivery of cost effective care, are still underused. A possible explanation for this is that most guidelines focus more on decision-making by individual professionals than on such multi-disciplinary care processes. ${ }^{47}$ As such, this points out the responsibility for health professionals and care managers to intensify their efforts for developing and implementing such multidisciplinary decision-support tools as part of their COPD programs.

As regards $H R Q L$, about half of the studies reporting this outcome observed statistical significant improvements on (limited) aspects of quality of life, but it was not always clear whether these improvements exceeded the minimal clinically meaningful difference. Moreover, the studies of Bourbeau and colleagues ${ }^{34}$ and Ries and colleagues ${ }^{22}$ showed that the positive impact did not sustain over time. Nevertheless, no studies reported a deterioration in HRQL and also there seemed to be no relation with the COPD severity of the included population or the setting in which the program was implemented. The latter is in contrast with a previous review of Niesink and colleagues, ${ }^{48}$ concluding that improved HRQL resulting from COPD disease management is limited to programs that are (at least partly) implemented in primary care.

Since only three studies undertook a (partial) economic evaluation, and the programs differ largely in terms of their contents as well as in the way they are operated in daily practice, the extent to which COPD care programs deliver value-for-money could not convincingly be demonstrated 
at the aggregate level. The provided illustrations on the potential cost effectiveness of specific COPD programs, however, may help to indicate whether there is sufficient opportunity for the program to be considered a worthwhile spending of scarce resources or to deliver a return on investment in the short or longer term. Although the illustrations are deliberately kept simple and therefore the figures should not be taken at face value, they do suggest that there is a fairly limited scope for the programs to save money or break-even. Again, similar observations have been published previously as well as reasons why this might be the case. Linden and Adler-Milstein ${ }^{12}$ for example point out that "the main opportunity for chronic care programs to realize short-term medical cost savings is via reductions in costly and avoidable hospital admissions" and "a focus on avoiding the first admission during the intervention period is critical given that hospitalizations are relatively rare events for the majority of the population" and that "individuals may only experience one over the entire course of the program." Therefore, close patient monitoring and effective integrated care delivery across community, primary, secondary and tertiary care are crucial to pick up exacerbation signs more timely and respond more pro-actively to achieve the desired cost effectiveness target. However, when having a closer look at the programs included in this review, it can be seen that only three are characterized by some degree of integration between care settings, whereas the majority is aimed at secondary care only, and therefore after the first hospitalization. As regards the disease severity of the included populations a similar observation can be made: most programs focus on the sicker part of the population, ie, GOLD stage 3. Of course, in a sicker population with higher hospitalization rates, a relatively lower number of admissions need to be avoided for the program to break even. But, such a narrowly focused program addresses only a small part of the population in a too late stadium to achieve the long term goal of chronic care management, which is reducing the increasing burden of COPD on society.

Finally, a couple of limitations of this review have to be taken into account when interpreting its results. First, determining whether a program consisted of two or more components was complicated by the fact that some papers only provided a limited description of their intervention. In case of doubt the paper was excluded and this may conservatively have limited the sample of included papers. However, when comparing the number of included studies in our review (ie, 20 studies) with the review of Adams and colleagues ${ }^{11}(\mathrm{n}=37)$ that also considered single component studies, the amount of included papers seems reasonable. Moreover, the multi-component programs included by Adams and colleagues ${ }^{11}$ were also picked up by our search. Finally, the results of this review should be interpreted in the light of the moderate methodological quality of its underlying studies, including for example at least seven studies that were underpowered to detect meaningful and statistical significant changes, as well as the lack of economic evaluations in the existing evidence base. Although the currently published data can be used to provide some indication about the potential cost effectiveness of COPD care programs, more and better health economic information will be needed to reduce uncertainty regarding the real impact of COPD care programs in daily practice. To obtain this, well-designed but practical multicentre health economic studies including broad representative patient samples, should be performed across care settings. ${ }^{49-50}$

\section{Conclusion}

This systematic review shows that identifying potentially cost effective multi-component COPD care programs remains a challenge given the scarcity of methodologically sound studies that demonstrate significant improvements on process, intermediate and end results of care. Nevertheless, also in the absence of 'perfect data', decisions regarding (future) investments in such care programs have to be made, and will be made, with the information that is available today. Estimations of potential cost effectiveness of specific programs as illustrated in this paper might support decision-makers in doing so. Further research, however, is needed to, firstly, substantiate the finding of this study that programs including three or more chronic care components are likely to be more cost effective than programs that only include the components 'delivery system design' and 'self-management support'. Finally it is recommended to carefully investigate whether programs that are more strongly based on multidisciplinary guidelines will indeed deliver more value for money than the current COPD care programs, especially when implemented across care settings and including broader patient samples.

\section{Acknowledgment}

This review study was supported by an unrestricted grant from PICASSO for COPD, an initiative of Pfizer B.V. and Boehringer Ingelheim B.V. in cooperation with research institute CAPHRI (School for Care and Public Health Research) of Maastricht University Medical Centre. 


\section{Disclosure}

The authors report no conflicts of interest in this work.

\section{References}

1. Wagner EH. Chronic disease management: What will it take to improve care for chronic illness? Eff Clin Pract. 1998;1:2-4.

2. Disease Management Association of America [online]. Accessed Jul 26, 2008. Available from: http://www.dmaa.org/phi_definition.asp.

3. Institute of Medicine of the National Academies. Crossing the quality chasm: the IOM health care quality initiative [online]. Accessed Jul 26, 2008. Available from: http://www.iom.edu.

4. World Health Organisation. How can chronic disease management programmes operates across care settings and organisations? Policy Brief 2008 [online]. Accessed Jul 26, 2008. Available from: http://www. euro.who.int/document/hsm/6_hsc08_ePB_9.pdf.

5. World Health Organisation. Chronic Obstructive Pulmonary Disease factsheet [online]. Accessed Jul 26, 2008. Available from: http://www. who.int/mediacentre/factsheets/fs315/en/index.html.

6. Robert Wood Johnson Foundation. Improving Chronic Illness Care [online]. Accessed Jul 26, 2008. Available from: http://www. improvingchroniccare.org.

7. Congressional Budget Office. An analysis of the literature on disease management programs, October 2004 [online]. Accessed Jul 26, 2008. Available from: http://www.cbo.gov/showdoc. $\mathrm{cfm}$ ? index $=5909 \&$ sequence $=0$.

8. Weingarten SR, Henning JM, Badamgarav E, et al. Interventions used in disease management programmes for patients with chronic illness - which ones work? Meta-analysis of published reports. $B M J$. 2002;325:925-932.

9. Ofman JJ, Badamgarav E, Henning JM, et al. Does disease management improve clinical and economic outcomes in patients with chronic diseases? A systematic review. Am J Med. 2004;117:182-192.

10. Mattke S, Seid M, Ma S. Evidence for the effect of disease management: is $\$ 1$ billion a year a good investment? Am J Manag Care. 2007;13:670-676.

11. Adams SG, Smith PK, Allan PF, et al. Systematic review of the chronic care model in chronic obstructive pulmonary disease prevention and management. Arch Intern Med. 2007;167:551-561.

12. Linden A, Milstein JA. Medicare disease management in policy context. Health Care Fin Review. 2008;29:1-11.

13. Hoffman C, Graf von der Schulenberg JM. The influence of economic evaluation studies on decision making: a European survey. Health Policy. 2000;52:179-192.

14. Williams I, Bryan S. Understanding the limited impact of economic evaluation in health care resource allocation: a conceptual framework. Health Policy. 2007;80:135-143.

15. Bodenheimer $\mathrm{T}$, Wagner $\mathrm{EH}$, Grumbach $\mathrm{K}$. Improving primary care for patients with chronic illness. JAMA. 2002;288:1775-1779.

16. Bodenheimer T, Wagner EH, Grumbach K. Improving primary care for patients with chronic illness: the chronic care model, Part 2. JAMA. 2002;288:1909-1914.

17. Steuten LM, Vrijhoef HJ, Van Merode GG, et al. The Health Technology Assessment-disease management instrument reliably measured methodological quality of health technology assessments of disease management. J Clin Epidemiol. 2004;57:881-888.

18. Drummond MF, O'Brien B, Stoddart GL, et al. Methods for the Economic Evaluation of Health Care Programmes. New York: Oxford University Press; 1987.

19. Culyer A, McCabe C, Briggs A, et al. Searching for a threshold, not setting one: the role of the National Institute for Health and Clinical Excellence. J Health Serv Res Policy. 2007;12:56-58.

20. Aiken LS, Butner J, Lockhart CA, et al. Outcome evaluation of a randomized trial of the PhoenixCare Intervention: program of case management and coordinated care for the seriously chronically ill. J Palliative Med. 2006;9:111-126.
21. Coultas D, Frederick J, Barnett B, et al. A randomized trial of two types of nurse assisted home care for patients with COPD. Chest. 2005;128:2017-2024.

22. Ries AL, Kaplan RM, Myers R, et al. Maintenance after pulmonary rehabilitation in chronic lung disease. Am J Respir Crit Care Med. 2003;167:880-888.

23. Solomon DK, Portner TS, Bass GE, et al. Part 2. Clinical and economic outcomes in the hypertension and COPD arms of a multicenter outcomes study. J Am Pharm Assoc. 1998;38:574-585.

24. Gourley GA, Portner TS, Gourley DR, et al. Part 3. Humanistic outcomes in the hypertension and COPD arms of a multicenter outcomes study. J Am Pharm Assoc. 1998;38:586-597.

25. Weinberger M, Murray MD, Marrero DG, et al. Effectiveness of pharmacist care for patients with reactive airways disease. JAMA. 2002;288:1594-1602.

26. Egan E, Clavarino A, Burridge L, et al. A randomized control trial of nursing-based case management for patients with chronic obstructive pulmonary disease. Lippincott's Case Manage. 2002;7:170-179.

27. Hermiz O, Comino E, Marks G, et al. Randomised controlled trial of home care of patients with chronic obstructive pulmonary disease. BMJ. 2002;325:938-942.

28. Jeffs KJ, Lim WK, Lim M, et al. The effect of a post acute respiratory outreach servive for patients with chronic obstructive pulmonary disease in hospital readmission rates. Respirology. 2005;10:239-243.

29. Smith BJ, Adams R, Appleton SL, et al. The effect of a respiratory home nurse intervention in patients with chronic obstructive pulmonary disease (COPD). Aust NZ J Med. 1999;29:718-725.

30. Poole PJ, Chase B, Frankel A, et al. Case management may reduce length of hospital stay in patients with recurrent admissions for chronic obstructive pulmonary disease. Respirology. 2001;6:37-42.

31. Rea H, McAuley S, Stewart A, et al. A chronic disease management programme can reduce days in hospital for patients with chronic obstructive pulmonary disease. Internal Med J. 2004;34:608-614.

32. Bourbeau J, Julien M, Maltais F, et al. Reduction of hospital utilization in patients with chronic obstructive pulmonary disease: a disease-specific self-management intervention. Arch Intern Med. 2003;163:585-591.

33. Gadoury MA, Schwartzman K, Rouleau M, et al. Self-management reduces both short- and long-term hospitalisation in COPD. Eur Respir J. 2005;26:853-857.

34. Bourbeau J, Collet JP, Schwartzman K, et al. Economic benefits of self-management education in COPD. Chest. 2006;130:1704-1711.

35. Hesselink AE, Penninx BWJH, Van der Windt DAWM, et al. Effectiveness of an education programme by a general practice assistant for asthma and COPD patients: results from a randomised controlled trial. Patient Educ Couns. 2004;55:121-128.

36. Steuten L, Vrijhoef B, Van Merode F, et al. Evaluation of regional disease management programme for patients with asthma or chronic obstructive pulmonary disease. Int $J$ Quality Health Care. 2006; 18:429-436.

37. Hernandez C, Casa A, Escarrabill J, et al. Home hospitalisation of exacerbated chronic obstructive pulmonary disease patients. Eur Respir J. 2003;21:58-67.

38. Casas A, Troosters T, Garcia-Aymerich J, et al. Integrated care prevents hospitalisations for exacerbations in COPD patients. Eur Respir J. 2006;28:123-130

39. Lee DTF, Lee IFK, Mackenzie AE, et al. Effects of a care protocol on care outcomes in older nursing home patients with chronic obstructive pulmonary disease. J Am Geriatr Soc. 2002;50:870-886.

40. Global Strategy for the Diagnosis, Management and Prevention of COPD, Global Initiative for Chronic Obstructive Lung Disease (GOLD) 2007 [online]. Accessed Jul 29, 2008. Available from: http://www. goldcopd.org.

41. Miravitlles M, Murio C, Guerrero T, et al. Costs of chronic bronchitis and COPD: a 1-year follow-up study. Chest. 2003;123:784-791.

42. Stone PW. Return-on-investment models. Appl Nurs Research. 2005;18:186-189. 
43. Brazier JE, Roberts J. The estimation of a preference-based measure of health from the SF-12. Med Care. 2004;42:851-859.

44. Effing T, Monninkhof E, Van der Valk P, et al. Self-management education for patients with chronic obstructive pulmonary disease. Cochrane Database Syst Rev. 2007;4:CD002990.

45. Kaper J, Wagena EJ, Willemsen MC, et al. Reimbursement for smoking cessation may double the abstinance rates: results of a randomized trial. Addiction. 2005;100:1012-1020.

46. Kaper J, Wagena EJ, Willemsen MC, et al. A randomized controlled trial to assess the effects of reimbursing the costs of smoking cessation therapy on sustained abstinence. Addiction. 2006;101:1656-1661.
47. Grol R. Between evidence-based [practice and total queslity management: the implementation of cost effective care. Int J Quality in Health Care. 2000;12:297-304.

48. Niesink A, Trappenburg JCA, de Weert-van Oene GH, et al. Systematic review of the effects of chronic disease management on quality-of-life in people with chronic obstructive pulmonary disease. Respir Med. 2007;101:2233-2239.

49. Glasgow RE, Magid DJ, Beck A, et al. Practical clinical trials for translating research to practice. Med Care. 2005;43:551-557.

50. Green LW. From research to 'best practices' in other settings and populations. Am J Health Behav. 2001;25:165-178. 